03;06

\title{
Полировка поверхности сверхтвердых материалов пучками газовых кластерных ионов
}

\author{
(C) А.Е. Иешкин ${ }^{1}$, К.Д. Кушкина ${ }^{1}$, Д.С. Киреев ${ }^{1}$, \\ Ю.А. Ермаков ${ }^{2}$, B.C. Черныш ${ }^{1,2}$ \\ ${ }^{1}$ Московский государственный университет им. М.В. Ломоносова, Москва \\ ${ }^{2}$ НИИ ядерной фризики им. Д.В. Скобельцына Московского \\ государственного университета им. М.В. Ломоносова, Москва \\ E-mail: ieshkin@physics.msu.ru
}

Поступило в Редакцию 16 августа 2016 г.

Проведено исследование влияния облучения газовыми кластерными ионами на топографию поверхности карбида кремния и алмаза. С помощью атомносиловой микроскопии показано, что воздействие на эти материалы кластерных ионов с энергией $10 \mathrm{keV}$ и дозами более $10^{16} \mathrm{~cm}^{-2}$ приводит к сглаживанию рельефа поверхности. Приведены оценки скорости травления и эффективности сглаживания рельефа в зависимости от толщины удаленного слоя вещества. С помощью спектроскопии комбинационного рассеяния света продемонстрировано отсутствие дефектов, вносимых облучением кластерными ионами в объем мишени.

DOI: 10.21883/PJTF.2017.02.44182.16459

Перспективными материалами современной электроники являются карбид кремния $(\mathrm{SiC})$ и алмаз. Они обладают высокой температурой Дебая, характеризующей устойчивость к внешним тепловым воздействиям, а также большими значениями теплопроводности и радиационной стойкости. В связи с этим активно исследуются возможности создания на их основе элементов силовой и высокочастотной электроники, в том числе с использованием технологий эпитаксиального осаждения многослойных структур [1-3]. Однако для формирования таких структур необходимо обеспечить высокое качество топографии и кристаллической структуры подложек и интерфейсных слоев. Это может представлять сложность, поскольку и карбид кремния, и алмаз являются сверхтвердыми материалами и с трудом поддаются 
механической обработке. Таким образом, актуальной задачей является исследование процессов сглаживания поверхности этих материалов без использования технологий, подразумевающих применение абразивной полировки. В данной работе проведено исследование эффекта сглаживания нанорельефа поверхности подложек из алмаза и карбида кремния с помощью ускоренных газовых кластерных ионов.

Образцы карбида кремния политипа $6 H-\mathrm{SiC}$ с кристаллографической ориентацией $\langle 0001\rangle$ и синтетического монокристаллического алмаза с ориентацией $\langle 111\rangle$, поверхность которых была предварительно отполирована механически, облучались ускоренными газовыми кластерными ионами на ускорителе МГУ им. М.В. Ломоносова [4]. Для формирования кластеров аргона с размерами в диапазоне от единиц атомов до 5000 атомов в указанном ускорителе используется охлаждение рабочего газа при его адиабатическом расширении через сверхзвуковое сопло. Затем полученные кластеры ионизируются электронным ударом, при этом они приобретают заряд в несколько элементарных единиц заряда и ускоряются разностью потенциалов $10 \mathrm{kV}$. Атомарные ионы и легкие кластеры с размерами менее 70 атомов отклоняются из пучка в постоянном магнитном поле, после чего осуществляется взаимодействие ускоренных кластерных ионов с мишенью. Давление остаточных газов в вакуумной камере образца во время эксперимента не превышало $6 \cdot 10^{-4} \mathrm{~Pa}$. Нужно отметить, что кинетическая энергия каждого отдельного атома, составляющего кластер, не превышает десятков электронвольт. Такие низкие значения энергии взаимодействия обеспечивают бездефектную обработку поверхности.

Состояние поверхности образцов до облучения и после него исследовалось с помощью комплекса NT-MDT Интегра спектра, использующего методики атомно-силовой микроскопии и конфокальной спектроскопии комбинационного рассеяния (КР) света. АСМ-изображения снимались в полуконтактном режиме, размеры сканов составляли $20 \times 20 \mu \mathrm{m}$ с разрешением $512 \times 512$ точек. Кроме того, были получены КР-спектры, позволяющие судить о структурных изменениях поверхности под действием облучения.

На рисунке, $a, d$ представлены АСМ-изображения поверхности карбида кремния и алмаза после механической обработки. На поверхности $\mathrm{SiC}$ видны хаотические линейно структурированные дефекты так называемый „алмазный фон“, т.е. царапины, оставленные абразивным материалом. Среднеквадратичная шероховатость поверхности,

2* Письма в ЖТФ, 2017, том 43, вып. 2 

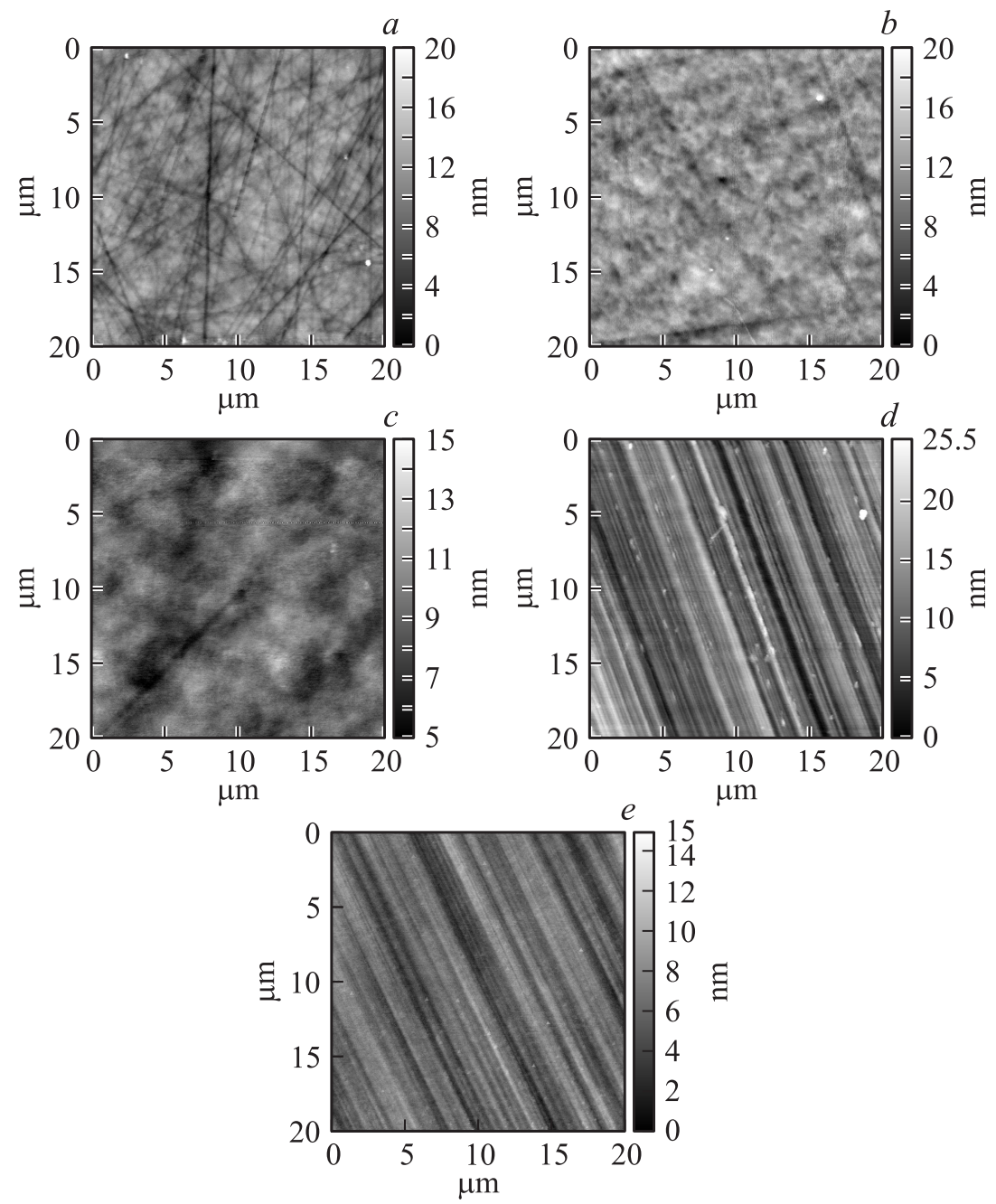

Атомно-силовые изображения топографии поверхности карбида кремния $(a-c)$ и алмаза $(d, e): a, d-$ до облучения, $b-$ после облучения с дозой $2.5 \cdot 10^{16} \mathrm{ion} / \mathrm{cm}^{2}, c, e-$ после облучения с дозой $5 \cdot 10^{16} \mathrm{ion} / \mathrm{cm}^{2}$. 
Среднеквадратичная шероховатость рельефа поверхности карбида кремния и алмаза при различных дозах облучения

\begin{tabular}{c|c|c}
\hline $\begin{array}{c}\text { Облучаемый } \\
\text { материал }\end{array}$ & $\begin{array}{c}\text { Доза облучения, } \\
10^{16} \mathrm{ion} / \mathrm{cm}^{2}\end{array}$ & $\begin{array}{c}\text { Среднеквадратичная } \\
\text { шероховатость, } \mathrm{nm}\end{array}$ \\
\hline \multirow{3}{*}{$\mathrm{SiC}$} & 0 & 2.41 \\
& 2.5 & 2.18 \\
& 5.0 & 1.09 \\
Алмаз & 0 & 3.23 \\
& 2.5 & 2.39 \\
& 5.0 & 1.62
\end{tabular}

полученная усреднением значений по трем сканам, составляла $2.41 \mathrm{~nm}$. В случае алмаза рельеф поверхности образован царапинами, имеющими одинаковое направление, с глубиной 2-6 nm и характерным периодом около $2 \mu \mathrm{m}$. Среднеквадратичная шероховатость исходного рельефа алмаза $3.23 \mathrm{~nm}$.

Дозы облучения кластерными ионами и соответствующие значения среднеквадратичной шероховатости приведены в таблице. Динамика изменения рельефа карбида кремния под действием облучения кластерными ионами отражена на рисунке, $b$ и $c$. Приведенные АСМ-изображения позволяют сделать вывод, что под действием облучения на поверхности $\mathrm{SiC}$ сначала становятся менее выраженными царапины и формируется хаотический рельеф, связанный с воздействием на поверхность ионов. Численное значение шероховатости при этом практически не уменьшается. Затем происходит сглаживание хаотических шероховатостей, в ходе которого снижается среднеквадратичная величина шероховатости.

Во время одного из этапов облучения часть образца была закрыта маской. Затем с помощью атомно-силового микроскопа измерялась высота полученной ступеньки травления. Определенная таким образом скорость удаления вещества составила $70 \mathrm{~nm} \mathrm{на} 10^{16} \mathrm{~cm}^{-2}$. Эта величина близка к значению, полученному в работе [5] при ускоряющем потенциале $20 \mathrm{kV}$, и несколько превосходит его за счет того, что в нашем эксперименте нижняя граница диапазона масс кластерных ионов была меньше. Следовательно, на образец попадали кластеры с большим значением энергии, приходящейся на один составляющий атом, эффек-

Письма в ЖТФ, 2017, том 43, вып. 2 
тивно увеличивающие интегральный коэффициент распыления. Общая толщина слоя, удаленного при кластерной обработке поверхности, составила $350 \mathrm{~nm}$.

В случае алмаза (см. рисунок, $e$ ) характер рельефа под действием облучения не изменился. Тем не менее значение шероховатости уменьшилось до значения $1.62 \mathrm{~nm}$. Определенная скорость травления составила $16 \mathrm{~nm}$ на $10^{16} \mathrm{ion} / \mathrm{cm}^{2}$, а толщина удаленного слоя $-80 \mathrm{~nm}$. Эти значения меньше аналогичных значений для карбида кремния, что объясняется большей энергией связи атомов на поверхности алмаза и недостаточно эффективным его распылением кластерами данных энергий.

В [6] на рамановском спектре алмазной пленки, облученной несепарированным по массам пучком кластерных ионов, обнаружен широкий пик в области $1600 \mathrm{~cm}^{-1}$. Его появление связано с наличием в пучке атомарных ионов, приводящих к графитизации и, следовательно, к ухудшению оптических и электрических характеристик алмаза. Для удаления графитизированного слоя авторы предлагают использовать последующее низкодозовое облучение химически активными кластерами.

В наших экспериментах из пучка частиц удалялись атомарные ионы и легкие кластеры. В результате на спектрах комбинационного рассеяния, снятых после облучения, никаких изменений отмечено не было, пик $1600 \mathrm{~cm}^{-1}$ не наблюдался, т.е. осуществлялась бездефектная обработка поверхности. Такие результаты подтверждают выводы статьи [7], в которой бездефектность травления монокристаллического кремния была продемонстрирована с помощью резерфордовского обратного рассеяния в режиме каналирования.

Таким образом, был продемонстрирован эффект сглаживания поверхности сверхтвердых монокристаллических веществ при облучении газовыми кластерными ионами. Такая технология является универсальной по отношению к обрабатываемому материалу, однако для наиболее эффективного воздействия на поверхность необходим выбор энергии и дозы облучения в зависимости от эффективности распыления и величины рельефа данного материала. Показано, что ускоренные кластерные ионы не вносят дефектов в кристаллическую структуру обрабатываемого вещества. Все это делает пучки ускоренных газовых кластерных ионов перспективным инструментом финишной обработки широкого спектра полупроводниковых и оптических материалов, в том числе сверхтвердых кристаллов.

Письма в ЖТФ, 2017, том 43, вып. 2 
Работа выполнена при поддержке Министерства образования и науки РФ, проект RFMEFI57814X0064.

\section{Список литературы}

[1] Лебедев А.А., Давыдов С.Ю., Сорокин Л.М., Шахов Л.В. // Письма в ЖТФ. 2015. T. 41. B. 23. C. 89-94. [Lebedev A.A. et al. // Tech. Phys. Lett. 2015. V. 41. N 12. P. $1156-1158]$.

[2] Вавилов В.С. // УФН. 1997. Т. 167. № 1. С. 17-22. [Vavilov V.S. // Phys. Usp. 1997. V. 40. P. 15-20].

[3] Kubota A., Fukuyama S., Ichimori Y., Touge M. // Diamond Relat. Mater. 2012. V. 24. P. 59-62. [Kubota A. et al. // Diamond Relat. Mater. 2012. V. 24. P. 59-62].

[4] Andreev A.A., Chernysh V.S., Ermakov Yu.A., Ieshkin A.E. // Vacuum. 2013. V. 91. P. 47-53. [Andreev A.A. et al. // Vacuum. 2013. V. 91. P. 47-53].

[5] Fathy D., Holland O.W., Liu R. et al. // Mater. Lett. 2000. V. 44. P. 248-252. [Fathy D. et al. // Mater. Lett. 2000. V. 44. P. 248-252].

[6] Toyoda N., Hagiwara N., Matsuo J., Yamada I. // Nucl. Instr. Meth. B. 1999. V. 148. P. 639-644. [Toyoda N. et al. // Nucl. Instr. Meth. B. 1999. V. 148. P. 639-644].

[7] Иешкин А.Е., Шемухин А.А., Ермаков Ю.А., Черныш В.С. // ВМУ. Сер. 3. 2016. № 1. C. 72-76. [Ieshkin A.E. et al. // Moscow University Physics Bulletin. 2016. V. 71. N 1. P. 87-90].

Письма в ЖТФ, 2017, том 43, вып. 2 